\title{
Amplified Fragment Length Polymorphism Diversity in Cephalosporium maydis from Egypt
}

\author{
Amgad A. Saleh, Kurt A. Zeller, Abou-Serie M. Ismael, Zeinab M. Fahmy, \\ Elhamy M. El-Assiuty, and John F. Leslie
}

First, second, and sixth authors: Department of Plant Pathology, Kansas State University, Manhattan 66506; and third, fourth, and fifth authors: Maize Section, Plant Pathology Research Institute, Agricultural Research Center, Giza, Egypt.

Current address of A. A. Saleh: National Agricultural Genetic Engineering Research Institute, Agricultural Research Center, Giza, Egypt. Accepted for publication 26 February 2003.

\begin{abstract}
Saleh, A. A., Zeller, K. A., Ismael, A.-S. M., Fahmy, Z. M., El-Assiuty, E. M., and Leslie, J. F. 2003. Amplified fragment length polymorphism diversity in Cephalosporium maydis from Egypt. Phytopathology 93:853-859.

Cephalosporium maydis, the causal agent of late wilt of maize, was first described in Egypt in the 1960s, where it can cause yield losses of up to $40 \%$ in susceptible plantings. We characterized 866 isolates of $C$. maydis collected from 14 governates in Egypt, 7 in the Nile River Delta and 7 in southern (Middle and Upper) Egypt, with amplified fragment length polymorphism (AFLP) markers. The four AFLP primer-pair combinations generated 68 bands, 25 of which were polymorphic, re-

sulting in 52 clonal haplotypes that clustered the 866 isolates into four phylogenetic lineages. Three lineages were found in both the Nile River Delta and southern Egypt. Lineage IV, the most diverse group (20 haplotypes), was recovered only from governates in the Nile River Delta. In some locations, one lineage dominated (up to $98 \%$ of the isolates recovered) and, from some fields, only a single haplotype was recovered. Under field conditions in Egypt, there is no evidence that $C$. maydis reproduces sexually. The nonuniform geographic distribution of the pathogen lineages within the country could be due to differences in climate or in the farming system, because host material differs in susceptibility and $C$. maydis lineages differ in pathogenicity.
\end{abstract}

Late wilt of maize was first recorded in Egypt in 1960 and the causal agent described as a new species, Cephalosporium maydis Samra, Sabet \& Hingorani $(18,19)$. Samra et al. (19) could differentiate between the late wilt fungus of maize (C. maydis) and other related Cephalosporium spp. (e.g., C. acremonium, $C$. gramineum, and $C$. gregatum) based on growth conditions, pathogenicity on maize, and microscopic description (morphology of hyphae, conidia, and conidiophores). They isolated $C$. maydis from both maize plants and soil in all of the Egyptian governates. They also demonstrated that the fungus generally was a soilborne pathogen, but that it can, in some cases, be isolated from seed of killed plants, suggesting that it also may be seedborne. Recently, Michail et al. (13) clearly demonstrated that $C$. maydis could be seedborne. Subsequent to its description in Egypt, late wilt of maize was reported in India (15), where it has become an important maize disease (22). Most recently, Pecsi and Nemeth (16) isolated and characterized $C$. maydis from maize plants with late wilt symptoms in Hungary. The geographic distribution of this fungus may be expanding, or its recognition may be increasing.

Much of the work done with this fungus has focused on control methods, mode of infection, and the effects of the fungus on physiological processes in the host. Although the most effective way to control late wilt is with resistant germ plasm (4), resistance to $C$. maydis appears to be polygenic $(3,8,9)$. Biological and chemical controls, as well as soil solarization, have been used as components of management programs for $C$. maydis $(1,5,16)$.

Only preliminary studies of molecular genetic variability in $C$. maydis are available. Zeller et al. (26) characterized 48 isolates of C. maydis from Egypt with isozymes and amplified fragment length polymorphisms (AFLPs). They observed no isozyme poly-

Corresponding author: J. F. Leslie; E-mail address: jfl@ksu.edu

Publication no. P-2003-0508-02R

(C) 2003 The American Phytopathological Society morphisms; however, based on the analysis of AFLP data, divided these 48 isolates into 25 clones and four putative phylogenetic lineages. Of the 69 AFLP primer-pair combinations that they examined, they identified 4 that collectively retained $\approx 90 \%$ of the distinctions made by the entire set of 69 . In this study, we used these four primer pairs to evaluate a large population sample from Egypt.

Our primary objective in the present study was to definitively assess the population structure of $C$. maydis in Egypt. Previous reports on genetic variability of $C$. maydis in Egypt are contradictory, with one suggesting high levels of phenotypic, and presumably genetic, variation (17), and the more recent study, utilizing molecular markers (26), suggesting relatively little genetic variation. In both cases, however, only a relatively small number of strains were examined. We also wanted to determine if the known lineages were uniformly distributed throughout the country, if other lineages existed that had not been detected previously, and the amount of genetic diversity within a lineage, all of which required the analysis of a larger set of strains. Such information could help direct resistance breeding strategies and determine whether internal quarantines should be instigated to slow the spread of the pathogen. More detailed understanding of pathogen populations also could provide clues to the evolutionary behavior of this organism as well as a base line against which other populations of this pathogen can be compared.

\section{MATERIALS AND METHODS}

Fungal cultures. C. maydis was isolated from maize plants with stalk rot or wilting symptoms as previously described (25). Recovery of $C$. maydis, even from heavily infested material, is difficult due to its slow growth and to the relative abundance of other more rapidly growing fungi, most commonly Fusarium spp. Isolates were identified as $C$. maydis by using morphological and microscopic characters (19). One fungal isolate was taken per 
plant, although it is possible to recover more than one genetically distinct isolate from the same plant (25), and were subcultured as single spores by dilution plating. Diseased stalks were collected by us and by other Agricultural Research Center employees and Egyptian Extension personnel. Many farms, especially in the Nile River Delta, are small ( $<0.5$ ha), and many farmers save seed or swap seed with their neighbors, which meant that, generally, it was not possible to identify the host hybrid or cultivar in any meaningful manner.

We recovered 866 isolates of $C$. maydis from 14 Egyptian governates (Table 1): 7 in the Nile River Delta and 7 in southern (Middle and Upper) Egypt. Isolates were routinely cultured on complete medium (CM) (2), and stored for long-term preservation as spore or hyphal fragment suspensions in $15 \%$ glycerol at $-70^{\circ} \mathrm{C}$.

DNA isolation. Small $\left(<2\right.$ to $\left.3 \mathrm{~mm}^{3}\right)$ pieces of $C$. maydis cultures were transferred from $\mathrm{CM}$ agar slants to $\mathrm{CM}$ broth and incubated on an orbital shaker $(150 \mathrm{rpm})$ for at least 3 days at room temperature $\left(25\right.$ to $\left.28^{\circ} \mathrm{C}\right)$. Mycelia were harvested by filtration through nongauze milk filters (Ken AG, Ashland, $\mathrm{OH}$ ), excess water was removed by blotting mycelia between clean paper towels, and dried mycelia were stored frozen at $-20^{\circ} \mathrm{C}$ until ground. Mycelia were ground to a powder under liquid nitrogen in a mortar with a pestle, placed into a $1.5-\mathrm{ml}$ microfuge tube, and stored at $-70^{\circ} \mathrm{C}$ until DNA was extracted. Fungal DNA was isolated with the cetyltrimethylammonium bromide method of Murray and Thompson (14) as modified by Kerényi et al. (7).

AFLP reactions. AFLP reactions (21) were performed as described by Zeller et al. (26) in a PTC-2000 Thermal Cycler (MJ Research Inc., Watertown, MA). We used the four primer-pairs selected by Zeller et al. (26) to analyze the $C$. maydis populations (Table 2). DNA was digested to completion with EcoRI and MseI and ligated to AFLP adaptors in a single step overnight at room temperature $\left(21\right.$ to $\left.24^{\circ} \mathrm{C}\right)$. The digested and ligated templates were diluted 1:20 with $\mathrm{H}_{2} \mathrm{O}$ prior to preamplification. Samples were preamplified with the following cycling conditions: one cycle of $94^{\circ} \mathrm{C}$ for $3 \mathrm{~min} ; 20$ cycles of $94^{\circ} \mathrm{C}$ for $30 \mathrm{~s}, 56^{\circ} \mathrm{C}$ for $60 \mathrm{~s}$, and $72^{\circ} \mathrm{C}$ for $60 \mathrm{~s}$; followed by a final extension step of $72^{\circ} \mathrm{C}$ for $5 \mathrm{~min}$; and then held at $4^{\circ} \mathrm{C}$ indefinitely. Preamplified reactions were diluted 1:50 with $\mathrm{H}_{2} \mathrm{O}$ prior to final specific AFLP amplification. EcoRI primers for specific amplification were end-labeled with $\gamma-{ }^{33} \mathrm{P}$ ATP. For final specific AFLP reactions, $1.3 \mu \mathrm{l}$ of diluted preamplification reactions were used and the final volume was $5 \mu \mathrm{l}$. The PCR program for the AFLP amplification was: one cycle of $94^{\circ} \mathrm{C}$ for $30 \mathrm{~s}, 65^{\circ} \mathrm{C}$ for $30 \mathrm{~s}$, and $72^{\circ} \mathrm{C}$ for $30 \mathrm{~s}$; this cycle was followed by 12 cycles in which the annealing temperature was lowered each cycle by $0.7^{\circ} \mathrm{C}$ from $65^{\circ} \mathrm{C}$ to $56^{\circ} \mathrm{C}$. After that, 23 cycles of $94^{\circ} \mathrm{C}$ for $30 \mathrm{~s}, 56^{\circ} \mathrm{C}$ for $30 \mathrm{~s}$, and $72^{\circ} \mathrm{C}$ for $60 \mathrm{~s}$ were performed; followed by a final extension step of $72^{\circ} \mathrm{C}$ for $5 \mathrm{~min}$, then held at $4^{\circ} \mathrm{C}$ indefinitely.

Analysis of AFLP data. AFLP fragments were separated in denaturing 6\% polyacrylamide gels (Long Ranger gel solution; FMC Scientific, Rockland, ME) with $1 \times$ TBE buffer $(100 \mathrm{mM}$ Tris base, $100 \mathrm{mM}$ boric acid, and $2 \mathrm{mM}$ EDTA, $\mathrm{pH}$ 8.0) in both the gels and the running buffer. Gels were run at a constant power of $60 \mathrm{~W}$ until the xylene cyanol (Sigma-Aldrich, St. Louis) marker had run approximately $22 \mathrm{~cm}$. After that, the gels were transferred to $3 \mathrm{MW}$ gel blotting paper (Midwest Scientific, Valley Park, MO) and dried before exposure to X-ray film at room temperature (Classic Blue Sensitive; Midwest Scientific) for 3 to 7 days.

AFLP fingerprints were scored manually as " 1 " for the presence of a band and " 0 " for the absence of a band, assuming that bands with the same molecular size in different individuals were homologous. We used the unweighted pair grouping by mathematical averages (UPGMA) subroutine of PAUP 4.8b (20) to construct phenograms (dendrograms), to determine the number of haplotypes, and to estimate genetic similarity among $C$. maydis isolates. Isolates initially were analyzed by governate to identify isolates with the same clonal haplotype. The clonal haplotypes from all 14 governates then were pooled in a nationwide analysis, and the duplicate haplotypes again discarded to give a set of unique haplotypes that were used for the remaining analyses. Final UPGMA similarities were calculated among the haplotypes with the Dice coefficient of similarity with the CLUSTER option of SAS (version 6.11; SAS Institute, Cary, NC). Genetic diversity was calculated based on lineage and haplotype data with Simpson's index (12), $D=\Sigma n_{i}\left(n_{i}-1\right) / N(N-1)$, where $n_{i}$ is the number of individuals in the $i$ th haplotype, and $N$ is the total number of individuals. As $D$ increases, diversity decreases; therefore, the reciprocal of Simpson's index $(1 / D)$ was used to yield an index that increases with increasing diversity. Similarities between populations in terms of the frequencies of the lineages present were tested by using a $\chi^{2}$ test for homogeneity.

The presence and frequencies of private alleles (loci with an allelic form found in one lineage, but not in the other three lineages) were identified with the program GDA (Lewis and Zaykin, Genetic Data Analysis: Computer program for the analysis of allelic data, version $1.0[\mathrm{~d} 16 \mathrm{c}]$ ). The degree of genetic differentiation among the four lineages was estimated with $\Phi_{S T}$ statistics (as an approximation of $F_{S T}$ ) among the clone-censored

TABLE 1. Cephalosporium maydis isolate distribution among 14 Egyptian governates, including the number of isolates, number of haplotypes from each governate, percentages of each lineage, and a summary of genetic diversity indices

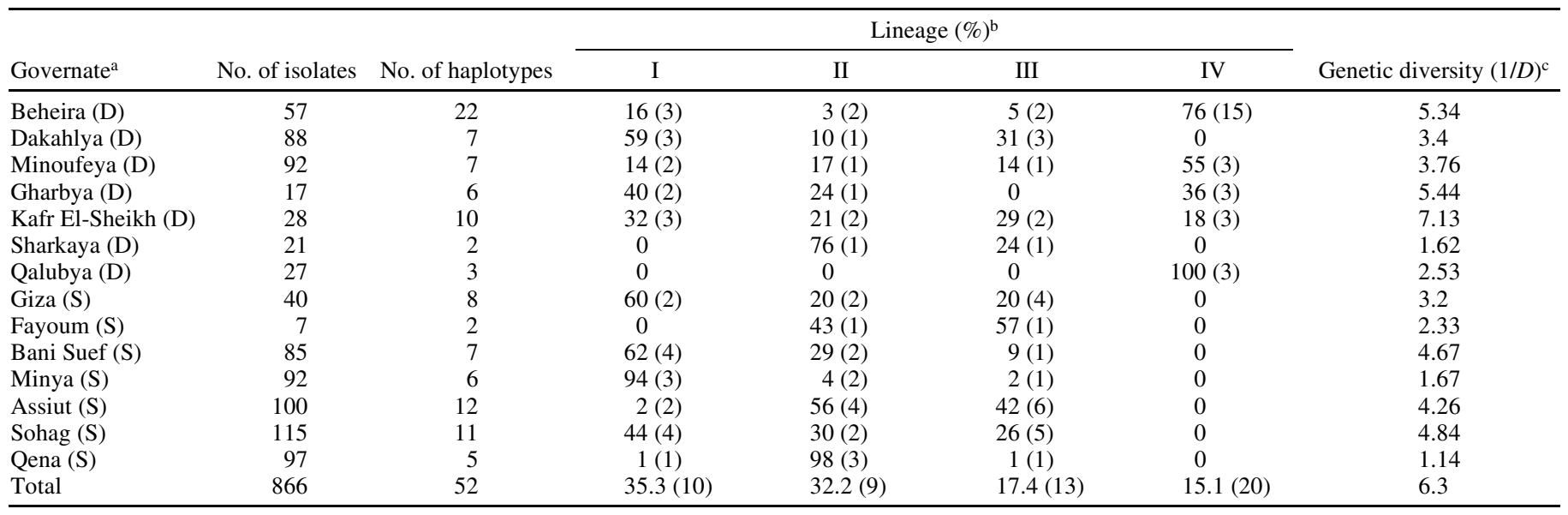

${ }^{a} \mathrm{D}=$ Nile River Delta and $\mathrm{S}=$ southern (Middle and Upper) Egypt.

$\mathrm{b}$ The number in parentheses is the number of haplotypes.

c $1 / D$ reciprocal form of Simpson's index $D, D=\sum n_{i}\left(n_{i}-1\right) / N(N-1)$, where $n_{i}$ is the number of individuals in $i$ th haplotype, and $N$ is the total number of individuals. 
haplotypes. Overall estimates of $\Phi_{S T}$, estimates of $\Phi_{S T}$ when individually lineages were serially removed, and all pairwise estimates between lineages were compared with the AMOVA procedures as implemented in GDA. GDA also was used to calculate $95 \%$ confidence intervals around these values with 1,000 bootstrap resamplings of the data.

\section{RESULTS}

Population structure. The four primer-pair combinations generated a total of 68 scorable AFLP markers, of which 25 were polymorphic (Table 2; Fig. 1). The EAA/MGA AFLP primer-pair combination did not generate any polymorphic bands (Table 2). UPGMA clustering analysis (Fig. 2) divided the isolates examined into two clusters (IV versus I, II, and III) at $88 \%$ similarity, divided them again at $91 \%$ similarity (I versus II and III), and for a third time at $94 \%$ similarity (II versus III). All of the haplotypes could be unambiguously assigned to one of the four clonal lineages. Lineage IV is more heterogeneous than the other three lineages. It is possible to split lineage IV into two sublineages, A and $\mathrm{B}$, at approximately $93 \%$ similarity, with the IVA sublineage containing 16 haplotypes and the IVB sublineage containing 4 haplotypes (Fig. 2). The average similarity among isolates within the population was $91 \%$, with a minimum similarity of $81 \%$. Between members of the same lineage, the minimum similarity was $88 \%$. Lineage IV had the lowest average genetic similarity within a lineage (95\%), while average similarities for lineages I, II, and III were somewhat higher, at 97, 97, and 98\%, respectively.

The number of isolates per haplotype was not uniform, with the two most frequent haplotypes, one from lineage I and the other from lineage II, accounting for more than half of the isolates. The five most frequent haplotypes contained over two-thirds of the collected isolates (Fig. 3), and were the only haplotypes found in both the Nile River Delta and in southern Egypt. This distribution is consistent with the hypothesis that the population is not reproducing sexually.

AFLP fingerprints of isolates from each governate were analyzed to determine population composition. Isolates belonging to lineages I, II, and III were recovered from both the Nile River Delta and southern Egypt, but isolates from lineage IV were recovered only from governates in the Nile River Delta (Table 1). Lineage IV had the most haplotypes, 20, the highest level of genetic diversity $(1 / D=3.16)$, and was the most genetically distant from the other lineages. The distribution of the lineages was not uniform across the country. For example, in some locations in the Delta, no lineage IV isolates were recovered (e.g., Dakahlya and Sharkaya) yet, in Qalubya, only isolates of lineage IV were recovered. The overall average percentage of lineage IV in the samples from the Nile River Delta governates was approximately $40 \%$ (Table 1).

Isolates of lineages I, II, and III were found throughout the country, and a single haplotype could dominate the samples from a governate. For example, a single haplotype of lineage II domi-

TABLE 2. Amplified fragment length polymorphism primer-pair combinations used in this study, and the total number of amplified bands and the number of polymorphic bands that resulted from polymerase chain reaction amplifications with each primer pair

\begin{tabular}{lcc}
\hline $\begin{array}{l}\text { Primer-pair } \\
\text { combination }^{\text {a }}\end{array}$ & $\begin{array}{c}\text { Total no. of } \\
\text { amplified bands }\end{array}$ & $\begin{array}{c}\text { No. of } \\
\text { polymorphic bands }\end{array}$ \\
\hline EAA/MCA & 16 & 6 \\
EAA/MCC & 24 & 10 \\
EAA/MCG & 16 & 9 \\
EAA/MGA & 12 & 0 \\
Total & 68 & 25 \\
\hline
\end{tabular}

${ }^{a} \mathrm{E}$ is EcoRI primer (5'-AGACTGCGTACCAATTC-3') followed by two base pairs (AA) and $\mathrm{M}$ is $\mathrm{Mse}$ I primer (5'-GATGAGTCCTGAGTAA-3') followed by two base pairs (CA, CC, CG, or GA). nated in Qena (92\% of the recovered isolates), whereas lineage I isolates dominated in Minya (94\% of the recovered isolates). Lineage I isolates were found in all governates except Sharkaya, Qalubya, and Fayoum; lineage II isolates in all governates except Qalubya; and lineage III isolates in all governates except Gharbya and Qalubya (Table 1). Nationally, the percentage of lineages I and II were 35 and $32 \%$, respectively (Table 1), and the percentage of lineage III and lineage IV both approximately $17 \%$. The relative frequency of lineages I, II, and III from the Nile River Delta was significantly different from these frequencies in southern Egypt, with lineage II proportionately more common in southern Egypt and lineage III more common in the Nile River Delta $\left(\chi^{2} \approx 20, P<0.001\right)$.

Haplotype structure and distribution. In all, 52 genetically distinct haplotypes were identified among the 866 isolates (Table 1; Fig. 2). Lineages I, II, III, and IV consisted of 10, 9, 13, and 20 haplotypes, respectively. Five haplotypes, representing $69 \%$ of the total isolates, were recovered from both the Nile River Delta and southern Egypt, and may be of greater economic importance and pathogenic significance than some of the rarer haplotypes. Of the five widely distributed haplotypes, two belonged to lineage I (combined, these contained $30 \%$ of the isolates), one to lineage II (containing $27 \%$ of the isolates), and two to lineage III (combined, these contained $12 \%$ of the isolates). Four of these five haplotypes (two from lineage I and one each from lineages II and III) were

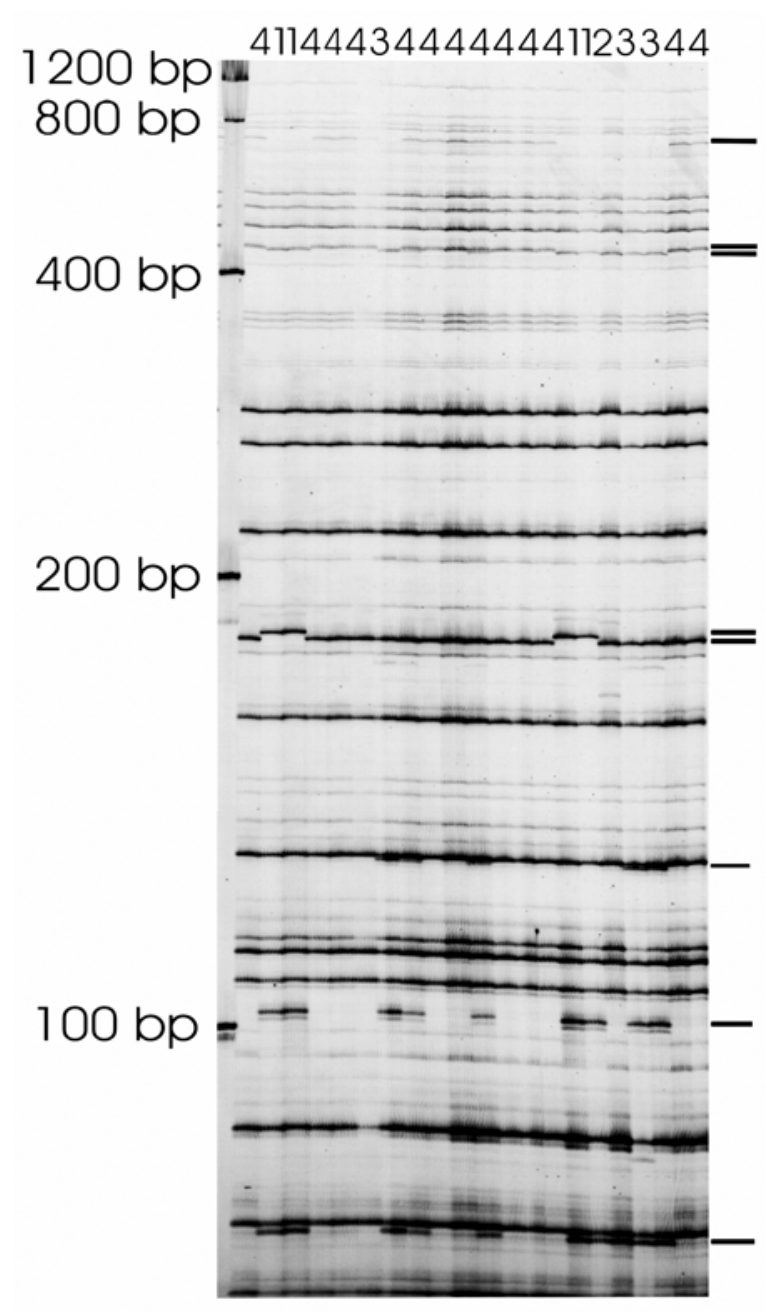

Fig. 1. A representative amplified fragment length polymorphism gel run for the identification of the lineages of Cephalosporium maydis. Bands used for diagnostic markers are noted by bars on the right of the figure. Lineage numbers for representative strains are given above those lanes at the top of the figure. Sizes of standard DNA fragments are given in base pairs on the left side of the figure. 
recovered from most of the governates. The fifth haplotype, which belongs to lineage III, was recovered from only three governates, one in the Nile River Delta (Dakahlya) and two in southern Egypt (Giza and Assiut). These three governates were the only ones from which all five of these widely distributed haplotypes were recovered.

Of the remaining 47 haplotypes (combined, these contained $31 \%$ of the isolates), 29 (16\% of the isolates) were recovered only from the Nile River Delta and 18 (15\% of the isolates) were recovered only from southern Egypt. The set of 29 haplotypes limited to the Nile River Delta included 4 of lineage I, 2 of lineage II, 3 of lineage III, and 20 of lineage IV, accounting for $42 \%$ of the isolates from this region. The 18 haplotypes recovered only in southern Egypt contained 4 of lineage I, 6 of lineage II, and 8 of lineage III, and accounted for $24 \%$ of the isolates from this region. The rate of recovery for these 47 haplotypes ranged from $0.2 \%$ (i.e., one isolate) to $8.2 \%$ of the total population. Of these 47 haplotypes, 38 were recovered from only a single governate, 5 from only two governates, and 4 from three or more governates.
These data indicate that a limited number of widely dispersed clonal genotypes dominate in $C$. maydis populations in Egypt. Rare and variant haplotypes, which could result from one or a few mutational steps, have a more restricted distribution.

Genetic diversity. Lineages I and III have almost the same genetic diversity $(1 / D=2.00)$. The least diverse lineage was lineage II $(1 / D=1.38)$. Overall, the level of genetic diversity in the populations from the Nile River Delta $(1 / D=7.03)$ was higher than in those from southern Egypt $(1 / D=4.85)$. Within the Nile River Delta, the Kafr El-Sheikh population was the most diverse $(1 / D=$ 7.13), followed by Gharbya and Beheira $(1 / D=5.44$ and 5.34, respectively). Of the 20 haplotypes of lineage IV, 15 were found in Beheira. The least diverse population in the Nile River Delta was from Sharkayia $(1 / D=1.62)$, where only two haplotypes were recovered. Within southern Egypt, the population from Sohag was the most diverse $(1 / D=4.84)$, followed by those from Beni Suef and Assiut $(1 / D=4.67$ and 4.26, respectively). The population from Qena was the least diverse $(1 / D=1.14)$, even though the sample of 97 isolates was relatively large.

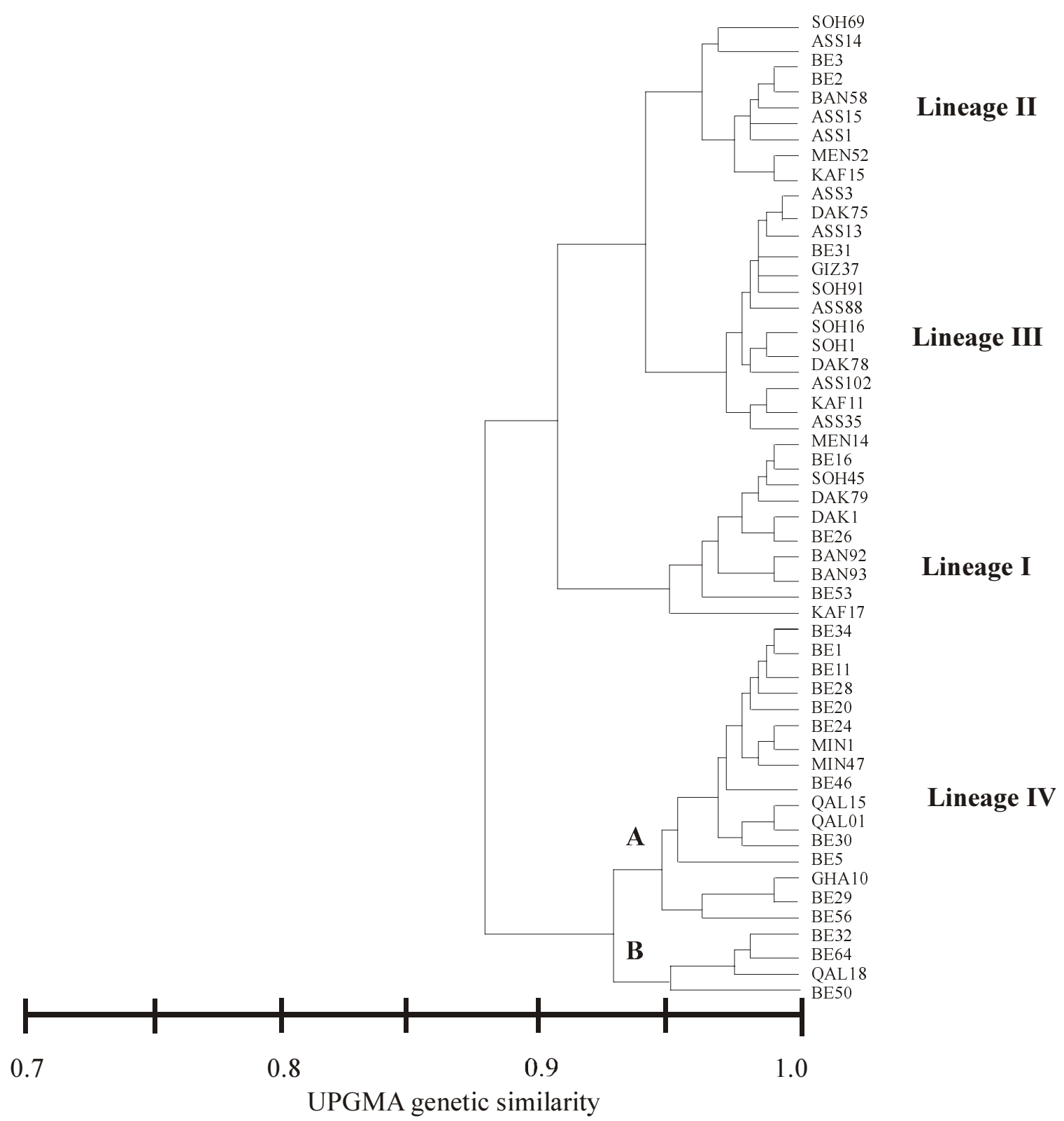

Fig. 2. Unweighted pair grouping by mathematical averages (UPGMA) phenogram of genetic similarity based on amplified fragment length polymorphism fingerprint data among censored haplotypes of Cephalosporium maydis from all governates. Designations to the right of each final branch are strain numbers. A and $\mathrm{B}$ are sublineages of lineage IV. 
Allelic differentiation among lineages. Of the 25 polymorphic loci, 7 were detected as private alleles. No private alleles were found in either lineage II or lineage III, but there were two private alleles in lineage I, and five private alleles in lineage IV (Table 3). The private alleles in lineage IV occurred in isolates from both sublineages. Frequencies of private alleles were 0.70 to 0.95 within the associated lineage. Lineages that were monomorphic for the private alleles were fixed for the rarer of the two alleles that were polymorphic in the polymorphic lineage(s).

The overall estimate of $\Phi_{S T}$ among isolates for the four lineages was 0.666 , and was significantly different from zero, with a $95 \%$ confidence interval of 0.586 to 0.731 . Pairwise comparisons of $\Phi_{S T}$ among the lineages ranged from 0.579 between lineages II and IV to 0.706 between isolates from lineages III and IV. All pairwise comparisons had confidence intervals indicating that they were significantly different from zero (Table 4). Similar results were obtained when individual lineages were serially removed from the data set. In these cases, estimates of $\Phi_{S T}$ were 0.637 to 0.693 , and $95 \%$ confidence intervals indicated that these estimates were significantly different from zero. Most of the observed allelic variance, $>58 \%$, is partitioned between, rather than within, lineages.

\section{DISCUSSION}

Genetic differentiation of lineages. The population genetic structure of $C$. maydis from Egypt determined in this study is consistent with the preliminary conclusions of Zeller et al. (26), who hypothesized that the $C$. maydis population in Egypt is clonal. To date, no sexual stage has been observed for this pathogen under field or laboratory conditions $(16,18,19)$. Therefore, our working hypothesis remains that natural populations of this pathogen should consist of asexually propagated clonal lineages, because no evidence for sexual recombination was observed in this study.

We retained the lineages defined by Zeller et al. (26) for the description of the population and, for three of these lineages (I, II, and III), the clustering of the strains within each group remains tight. Lineage IV could be divided into two sublineages at a genetic distance of 0.07 , which is greater than the genetic distance between lineages II and III. Both sublineages share all of the pri- vate alleles that are unique to lineage IV, suggesting that these sublineages are part of a single unit rather than separate entities. One of the sublineages, IVB, is represented by only four haplotypes, which makes the significance of this differentiation even less clear. Based on our sample, any undetected lineages in Egypt are present at a frequency of $<0.4 \%$.

Within lineage similarities were generally $>95 \%$, while similarities between lineages ranged from 88 to $94 \%$. For isolates that are so genetically similar, the relative proportion of private alleles $(13 \%)$ is high, as was the frequency of the private alleles within a lineage (70 to $95 \%$ ). These results suggest that there is little, if any, genetic exchange between these lineages, either currently or in the recent past, and that this genetic isolation has allowed some allelic forms to drift toward fixation. That all seven lineage-specific private alleles are the alleles that are most frequent reinforces this conclusion. The hypothesis that these lineages are genetically isolated also is consistent with the relatively high estimated $\Phi_{S T}$ values, both overall $(\approx 0.66)$, and in the pairwise comparisons of lineages (ranging from 0.58 to 0.71 , Table 4). We interpret these data to mean that these AFLP-based lineages represent genetically isolated clonal groups that are evolving in response to mutation, genetic drift, or selection.

The previous analysis of molecular variation in C. maydis (26) found strong bootstrap support for the separation of the four lineages, but such support is lacking in this study. There are at least three possible causes for this lower level of support. The simplest is that bands from the different lineages, although the same size, are not homologous. A second possibility is that the increased number of haplotypes makes the identification of significant differences more difficult. A third is that the increased numbers of haplotypes within the lineages, and the increased overlap indicated by shared polymorphisms tend to blur the statistical distinctiveness of the lineages resulting from UPGMA analyses. We expect that, if the current set of isolates was analyzed on the basis of the banding patterns for the previous set of 69 AFLP primer pairs, then the statistical support for the separateness of the lineages would be far greater.

If the results of the present study are combined with those of the previous study (26), the total number of haplotypes known is

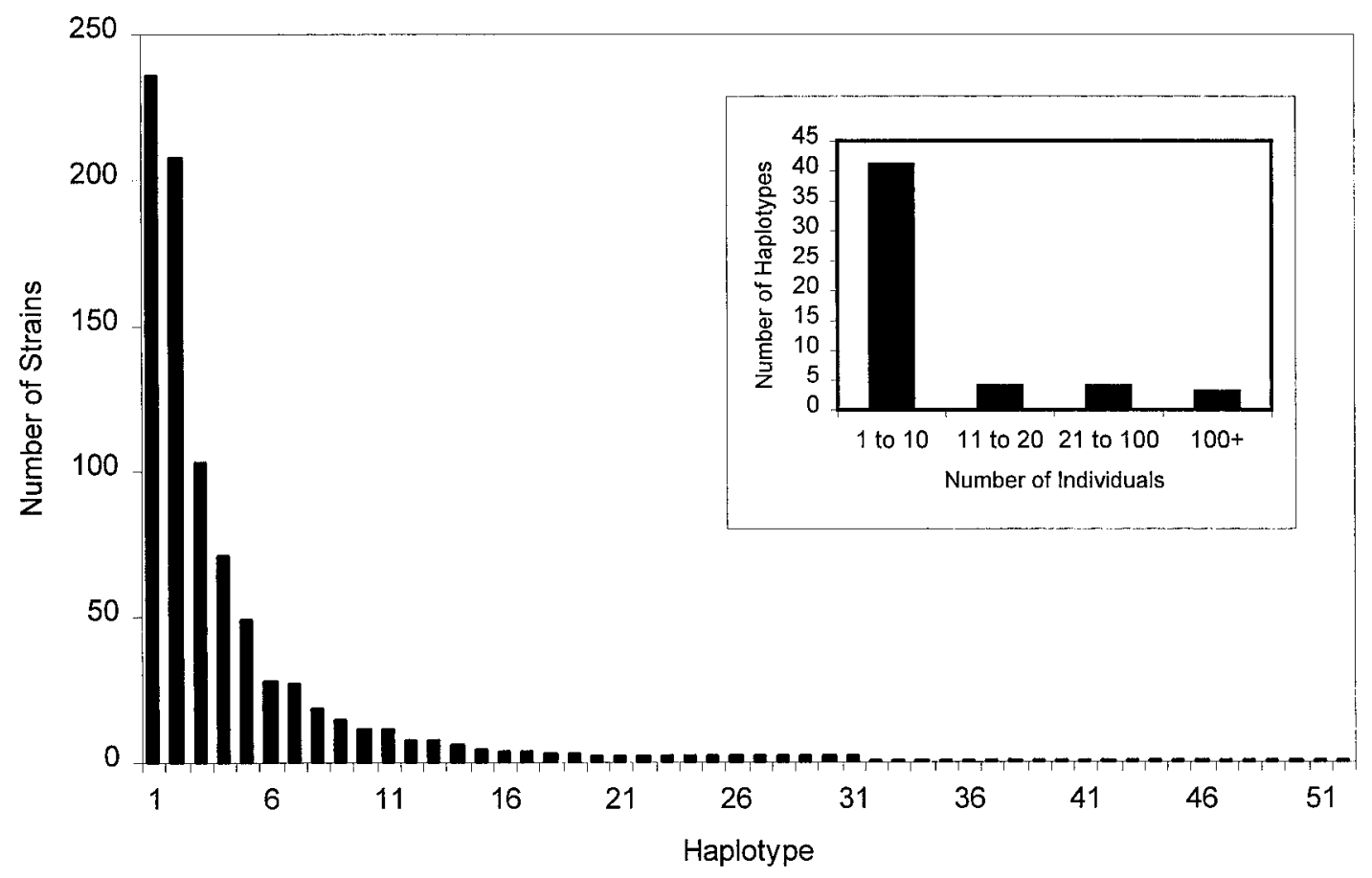

Fig. 3. Number of Cephalosporium maydis isolates per haplotype in population from maize in Egypt. Inset: number of $C$. maydis haplotypes containing various numbers of isolates. 
lineage I, 18; lineage II, 13; lineage III, 16; and lineage IV, 21. Strains representing 9/68 haplotypes were identified in both studies and account for 20/48 isolates in the previous study and $687 / 866$ isolates in the present study. These nine haplotypes include the five most common haplotypes in the present study, one additional haplotype each from lineages I and II, and two haplotypes from lineage IVA. No isolates representing lineage IVB were found in the earlier study. In all, 16 haplotypes were unique to the Zeller et al. (26) preliminary study and 43 haplotypes, representing $21 \%$ of the isolates examined, were unique to the present study. Two haplotypes from lineage I in the present collection also were present in a set of 10 isolates of $C$. maydis collected in the 1980s. One of these haplotypes was represented by 49 isolates collected from eight governates in the present study, and the other by 12 isolates collected from three governates. This pattern is consistent with the hypothesis of clonal reproduction by $C$. maydis, although the relative frequencies of individual haplotypes may vary with time and sampling pattern.

Geographic distribution of the lineages. Isolates of lineages I, II, and III were recovered from both the Nile River Delta and southern Egypt, but isolates of lineage IV were recovered only from the Nile River Delta governates. The nonuniform distribution of lineages leaves many important questions unanswered. For example, are there environmental variables, host germ plasm, or cultural practices associated with the distribution of these lineages? What is unusual about the Beheira governate that is responsible for the relatively large number (21) of haplotypes recovered there?

The level of genetic diversity we detected in the $C$. maydis populations varied by lineage and by geographic region. Pathotype diversity of Colletotrichum lindemuthianum and the diversity of cultivated cultivars of Phaseolus vulgaris in Mexico were correlated (6), which led to the conclusion that the cultivation of resistant cultivars may lead to an increase in pathogen diversity, especially if a nonagricultural Phaseolus host is found in close proximity to cultivated forms. Such increased variation is predicted by some to be a general property of diversified agroecosystems (10). Our results are consistent with such a hypothesis because the number and variety of maize cultivars planted generally is higher in the Nile River Delta than it is elsewhere in the country. This diversity or heterogeneity could select for more diverse populations of $C$. maydis, and efforts to understand this relationship between host and pathogen diversity need to be examined in more detail.

Cephalosporium maydis also is known as a maize pathogen in India $(15,23)$ and Hungary (16). The pathogenic capabilities and the relationship of these populations of $C$. maydis to those found in Egypt are presently unknown. An assessment of the genetic population structure of these other populations of $C$. maydis could help to answer some important questions. For example, what is the origin of $C$. maydis? Do these pathogenic populations share lineages with each other or with the Egyptian populations? Are the levels of genetic diversity in these populations comparable to those from Egypt? Is the genetic diversity within the other populations suggestive of nearly exclusive asexual reproduction?

Implications for the management of late wilt disease. Correlations between molecular genotype or clonal genotype and pathogenic capabilities of different lineages have been noted in other crop pathogens (e.g., Colletotrichum lindemuthianum [6] and Magnaporthe grisea [11,24]). In these systems, these relationships have been exploited to increase understanding of the pathogenic interactions between host and fungal pathogen and to improve breeding and disease-control strategies. Our data suggest that similar strategies could be applicable for the management of late wilt caused by $C$. maydis in Egypt.

The lineages differ in their abilities to colonize maize plants, their relative aggressiveness in single culture inoculations (25), or both. Isolates of lineage IV were highly aggressive in singleinfection experiments on a susceptible maize cultivar, but were the least competitive in multiple-infection experiments. Environmental conditions, plant genotype, and associated resistance characters, as well as relative differences in persistence and competitive ability, all could influence the field distribution pattern of the lineages. The frequency and geographic distribution of $C$. maydis lineages throughout Egypt is important for improving resistancebreeding and variety, cultivar, or hybrid deployment efforts, because lineage IV can colonize some host lines that are resistant or tolerant to the other lineages (25).

The population structure of $C$. maydis provides clues to what may be the best ways to manage late wilt of maize. At present, host plant resistance appears to be the best strategy to control late wilt. Systematic field tests of maize germ plasm against individual fungal lineages, and perhaps even haplotypes, need to be conducted to confirm and extend the results of Zeller et al. (25); however, for now, all lineages of the pathogen should be used to challenge host material during the development of resistant germ plasm. Deployment of host resistance in a manner that does not select for further diversification of the existing clonal lineages and that takes advantage of their current distribution is one way to manage late wilt and to reduce exposure to it. For example, maize germ plasm that is susceptible to lineage IV might be well suited

TABLE 3. Distribution of loci with private alleles limited to a single lineage of Cephalosporium maydis ${ }^{\mathrm{a}}$

\begin{tabular}{|c|c|c|c|c|c|c|c|c|}
\hline \multirow[b]{2}{*}{ Locus } & \multirow[b]{2}{*}{ Lineage } & \multirow[b]{2}{*}{ Allele } & \multicolumn{2}{|c|}{ Entire country } & \multicolumn{2}{|c|}{ Southern Egypt } & \multicolumn{2}{|c|}{ Nile River Delta } \\
\hline & & & Clones & Isolates & Clones & Isolates & Clones & Isolates \\
\hline EAAMCC11 & I & Presence & $9 / 10$ & $305 / 306$ & $6 / 6$ & $216 / 216$ & $5 / 6$ & $89 / 90$ \\
\hline EAAMCC12 & I & Absence & $9 / 10$ & $305 / 306$ & $6 / 6$ & $216 / 216$ & $5 / 6$ & $89 / 90$ \\
\hline EAAMCG01 & IV & Presence & $14 / 20$ & $116 / 131$ & $0 / 0$ & $0 / 0$ & $14 / 20$ & $116 / 131$ \\
\hline EAAMCG04 & IV & Presence & $17 / 20$ & $126 / 131$ & $0 / 0$ & $0 / 0$ & $17 / 20$ & $126 / 131$ \\
\hline EAAMCG05 & IV & Presence & $16 / 20$ & $125 / 131$ & $0 / 0$ & $0 / 0$ & $16 / 20$ & $125 / 131$ \\
\hline EAAMCC01 & IV & Presence & $19 / 20$ & $129 / 131$ & $0 / 0$ & $0 / 0$ & $19 / 20$ & $129 / 131$ \\
\hline EAAMCC23 & IV & Absence & $14 / 20$ & $100 / 131$ & $0 / 0$ & $0 / 0$ & $14 / 20$ & $100 / 131$ \\
\hline
\end{tabular}

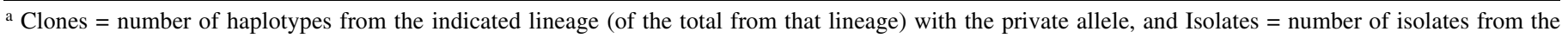
indicated lineage (of the total from that lineage) with the private allele.

TABLE 4. Pairwise comparisons of $\Phi_{S T}$ with clone-censored isolates of the four lineages of Cephalosporium maydis ${ }^{\mathrm{a}}$

\begin{tabular}{|c|c|c|c|}
\hline & Lineage 2 & Lineage 3 & Lineage 4 \\
\hline Lineage 1 & $0.660(0.489-0.759)$ & $0.702(0.571-0.783)$ & $0.663(0.544-0.747)$ \\
\hline Lineage 2 & $\ldots$ & $0.585(0.377-0.725)$ & $0.579(0.368-0.710)$ \\
\hline Lineage 3 & $\ldots$ & $\ldots$ & $0.706(0.622-0.776)$ \\
\hline
\end{tabular}

${ }^{\mathrm{a}} \Phi_{S T}$ and $95 \%$ confidence intervals from 1,000 bootstrap resamplings of the data set calculated with GDA. 
for southern Egypt but not for the Nile River Delta. Thus, $C$. maydis population composition could have very significant impact on maize germ plasm development and distribution in Egypt.

\section{ACKNOWLEDGMENTS}

This research was supported in part by the Agricultural Technology Utilization and Transfer project 58-3148-7-057 from the United States Agency for International Development (Cairo), and by the Kansas Agricultural Experiment Station. Manuscript 02-265-J from the Kansas Agricultural Experiment Station, Manhattan. We thank A. Beyer and B. van Scoyoc for technical assistance.

\section{LITERATURE CITED}

1. Abdel-Hamid, M. S., Abdel-Momeim, M. F., El-Shafey, H. A., and ElDeeb, S. T. 1981. Biological control of late-wilt disease of maize caused by Cephalosporium maydis. Agric. Res. Rev. 59:253-260.

2. Correll, J. C., Klittich, C. J. R., and Leslie, J. F. 1987. Nitrate nonutilizing mutants of Fusarium oxysporum and their use in vegetative compatibility tests. Phytopathology 77:1640-1646.

3. El-Itriby, H. A., Khamis, M. N., El-Demerdash, R. M., and El-Shafey, H. A. 1984. Inheritance of resistance to late-wilt (Cephalosporium maydis) in maize. Pages 29-44 in: Proc. 2nd Meditter. Conf. Genet. Cairo.

4. El-Shafey, H. A., El-Shorbagy, F. A., Khalil, I. I., and El-Assiuty, E. M. 1988. Additional sources of resistance to the late-wilt disease of maize caused by Cephalosporium maydis. Agric. Res. Rev. 66:221-230.

5. Fayzalla, E. A., Sadik, E. A., Elwakil, M. A., and Gomah, A. A. 1994. Soil solarization for controlling Cephalosporium maydis: The cause of late wilt disease in Egypt. Egypt. J. Phytopathol. 22:171-178.

6. Gonzalez, M., Rodriguez, R., Zavala, M. E., Jacobo, J. L., Hernandez, F., Acosta, J., Martinez, O., and Simpson, J. 1998. Characterization of Mexican isolates of Colletotrichum lindemuthianum by using differential cultivars and molecular markers. Phytopathology 88:292-299.

7. Kerényi, Z., Zeller, K., Hornok, L., and Leslie, J. F. 1999. Standardization of mating-type terminology in the Gibberella fujikuroi species complex. Appl. Environ. Microbiol. 65:4071-4076.

8. Labib, H. A. 1972. A study of the inheritance of resistance to late-wilt disease in maize caused by Cephalosporium maydis. Ph.D. diss. Fac. Agric. Ain Shams University, Cairo.

9. Labib, H. A., Abdel-Rahim, M. F., Salem, A., and Abdel-Fattah, A. 1975. D.C. 19, a new maize hybrid seed resistant to late-wilt disease caused by Cephalosporium maydis. Agric. Res. Rev. 53:1-4.

10. Lenné, J. M., and Ortiz, R. 2002. Agrobiodiversity in pest management. Pages 309-319 in: Sorghum and Millets Diseases. J. F. Leslie, ed. Iowa
State Press, Ames

11. Levy, M., Correa-Victoria, F. J., Zeigler, R. S., Xu, S., and Hamer, J. E. 1993. Genetic diversity of the rice blast fungus in a disease nursery in Colombia. Phytopathology 83:1427-1433.

12. Magurran, A. E. 1988. Ecological Diversity and Its Measurement. Princeton University Press, Princeton, NJ.

13. Michail, S. H., Abo-Elseoud, M. S., and Nour-Eldin, M. S. 1999. Seed health testing of corn for Cephalosporium maydis. Acta Phtytopathol. Entomol. Hung. 34:35-41.

14. Murray, M. G., and Thompson, W. F. 1980. Rapid isolation of high molecular weight plant DNA. Nucleic Acids Res. 8:4321-4325.

15. Payak, M. M., Lal, S., Lilaramani, J., and Renfro, B. L. 1970. Cephalosporium maydis-A new threat to maize in India. Indian Phytopathol. 23:562-569.

16. Pecsi, S., and Nemeth, L. 1998. Appearance of Cephalosporium maydis Samra, Sabet and Hingorani in Hungary. Facult. Landbouw. en Toegepaste Biolog. Wetenschappen, Univ. Gent 63:873-877.

17. Sabet, K. A., Samra, A. S., and Mansour, I. M. 1966. Late-wilt of maize and a study of the causal organism. Pages 8-45 in: Investigations on Stalk-Rot Diseases of Maize in U.A.R. A. S. Samra and K. A. Sabet, eds. Ministry of Agriculture, Government Printing Offices, Cairo.

18. Samra, A. S., Sabet, K. A., and Hingorani, M. K. 1962. A new wilt disease of maize in Egypt. Plant Dis. Rep. 46:481-483.

19. Samra, A. S., Sabet, K. A., and Hingorani, M. K. 1963. Late wilt disease of maize caused by Cephalosporium maydis. Phytopathology 53:402-406.

20. Swofford, D. L. 1999. PAUP: Phylogenetic Analysis Using Parsimony (and Other Methods), Version 4.8b. Sinauer Associates, Sunderland, MA.

21. Vos, P., Hogers, R., Bleeker, M., Reijans, M., van de Lee, T., Hornes, M., Frijters, A., Pot, J., Peleman, J., Kuiper, M., and Zabeau, M. 1995. AFLP: A new concept for DNA fingerprinting. Nucleic Acids Res. 23:4407-4414

22. Ward, E., and Bateman, G. L. 1999. Comparison of Gaeumannomycesand Phialophora-like fungal pathogens from maize and other plants using DNA methods. New Phytol. 141:323-331.

23. White, D. G., ed. 1999. Compendium of Corn Diseases. 3rd ed. The American Phytopathological Society, St. Paul, MN.

24. Zeigler, R. S., Cuoc, L. X., Scott, R. P., Bernardo, M. A., Chen, D. H., Valent, B., and Nelson, R. J. 1995. The relationship between lineage and virulence in Pyricularia grisea in the Philippines. Phytopathology 85:443:451.

25. Zeller, K. A., Abou-Serie, M. I., El-Assuity, E. M., Fahmy, Z. M., Bekheet, F. M., and Leslie, J. F. 2002. Relative aggressiveness of four clonal lineages of Cephalosporium maydis from Egypt towards greenhouse-grown maize. Plant Dis. 86:373-378.

26. Zeller, K. A., Jurgenson, J. E., El-Assiuty, E. M., and Leslie, J. F. 2000. Isozyme and amplified fragment length polymorphisms from Cephalosporium maydis in Egypt. Phytoparasitica 28:121-130. 